\title{
BIM-based facility management models for existing buildings
}

\author{
Karim Soliman, Khalid Naji, Murat Gunduz*, Onur B. Tokdemir, Faisal Faqih and \\ Tarek Zayed \\ Department of Civil and Architectural Engineering, Qatar University, Doha, Qatar \\ *Corresponding Author:mgunduz@qu.edu.qa
}

Submitted : 22/08/2020

Revised :28/12/2020

Accepted :08/01/2021

\begin{abstract}
Building Information Modeling (BIM) is mainly used for the design and construction of new buildings. However, one of the main challenges facing BIM adoption for existing or old buildings constructed without consideration for their modeling is obtaining raw and accurate building data and converting it to the BIM model. Based on this challenge, this study develops a framework that uses different data capture techniques for existing buildings and then transforms this captured data into 3D BIM models, through which it can improve its management processes as facilities during their service life. Specifically, 3D laser scanning techniques were used to capture indoor building data, while drones equipped with high-definition cameras (UAV) were used to capture outdoor building data such as geometric dimensions, material shapes, surfaces, and various shapes. Then, the captured data was converted into a high-resolution 3D model. This has verified the accuracy of this engineering model by converting the twodimensional engineering plans to three-dimensional through the well-known engineering design tools. Moreover, the 3D model has been integrated with the Web Based Building Management System (BMS) platform. This research framework helps in developing engineering facility management processes and modern digital transformation processes that aim at speeding up facility management during their service period using modern technologies. This study aims to develop current knowledge in the construction industry and facility management by reviewing a comprehensive understanding of how to use modern technologies to obtain various information to develop BIM models for existing and nonmodeled buildings in order to exploit and integrate them with advanced facility management systems and platforms, which constitutes a major progress in this field allowing to save a lot of effort and money in the future.
\end{abstract}

Keywords: Building engineering; Building information modeling; Building management system; 3D laser scanning; Facility management; Unmanned aerial vehicles UAVs.

\section{INTRODUCTION}

Precedent studies mainly focused on the design and construction phases of projects. In contrast, most existing facilities are traditionally designed using CAD and have yet to benefit from BIM integration (Barki et al. 2015; Fadli et al. 2016). BIM has been used in the construction industry for decades. However, its main focus is on design and construction phases. This is considered a small fraction in terms of time and cost concerning the life cycle (D-C) cost of a building. 
One major obstacle facing the use and optimization of BIM for existing buildings is the accuracy of developing data capture and BIM model generation (Volk et al. 2014). According to Wong et al. (2018), challenges involving data acquisition for accurate as-built BIM model generation and interoperability are hindering its implementation in Facilities Management (FM). Carbonari et al. (2018) demonstrated that the accurate generation of BIM models is more complicated for existing buildings than for newly built ones. Pärn et al. (2017) highlighted the lack of interoperability of BIM and existing computer-aided facilities management (CAFM) as one of the barriers to the adoption of BIM in existing buildings.

This study aims to develop a framework to generate a BIM model for existing buildings first by using a combination of diverse data-capture technique and then integrating the BIM model with the BMS system. As such, 3D laser scanning was used for indoor data capture. In contrast, unmanned aerial vehicles (UAVs) were used for accurate outdoor data capture of the presented case study. Furthermore, to examine the challenges and potential solutions to integrating existing BMS with BIM, the framework developed in this study is used as a case study for the building (Central Stores Facility) located at Qatar University. This study uses two main 3D data capture techniques and the subsequent integration BIM-BMS. The findings from this study aim to support the generation of BMS integrated BIM models.

This study was conducted in the Central Stores Facility at Qatar University. Three different capturing techniques were used: 2D-to-3D BIM, scan-to-BIM, and UAV-to-BIM. While the 2D-to-3D BIM technique provides absolute accuracy in terms of digital representation of architectural, structural, MEP, electrical/ fixtures and other building systems; it has major disadvantages to be adopted by the industry. These include the complexity involved in the 2Dto-3D conversion process based on $\mathrm{CAD}$, the amount of time needed for the conversion and the generated 3D BIM model lacking other attributes such as as-built textures or the existing realism of the captured facility.

The scan-to-BIM capturing technique is robust in terms of time and suitable for capturing any internal details for a facility in terms of architecture and structural systems such as floors, roofs, columns, dropped beams as well as electrical fixtures. However, it has a limitation of not capturing many components such as hidden electro, mechanical and firefighting systems. In such a case, the 2D-to-3D BIM can be adopted with much less time and effort limited to these systems only. In the case study presented, the Central Stores facility had an exposed ceiling structure, where most systems are exposed to lidar (scan-to-BIM) capturing technique. The UAV capturing technique is very much suitable for all exterior details of a typical facility such as roof structures and facades with a high level of accuracy and detail such as dimensions, colors, and textures. Both techniques scan-to-BIM and UAV-to-BIM showed highly accurate 3D BIM models when compared to the original 2D as-built CAD data related to the case study.

\section{RESEARCH BACKGROUND AND KNOWLEDGE GAPS}

BIM models generation for existing buildings remains a challenge due to the difficulties involved in the accurate initial data capture for BIM modelling (Volk et al. 2014), and many of these buildings do not even have as-built drawings for $\mathrm{CAD}$ to BIM conversion. Accurate data capture is crucial for the full utilization of BIM functionality for existing buildings.

Established procedures for modelling these buildings generally begin with importing CAD drawings into BIM software, providing a base 2D drawing, on which the 3D model is developed manually (Barki et al. 2015; Fadli et al., 2016). However, converting CAD to a 3D BIM model is restricted by the accuracy and automation level (Yin et al. 2018). Besides, manually entering data into a BIM model of a large building is cumbersome; hence, it is essential to develop a framework for capturing and incorporating existing building data. 
Although as-built data and drawings can be used to extract data to generate BIM for existing buildings, many buildings, for various reasons, do not have such data available. Recent hardware technology developments have made data capture an option in situations where as-built data of an existing building are not available. However, irrespective of the method used to generate the BIM model, its accuracy is essential for the use in FM (Patacas et al., 2020; El Ammari et al., 2019).

Two key data capture techniques can be used for existing buildings, namely, noncontact and contact methods. Noncontact methods may be image-based, and they include laser scanning, photography, and videogrammetry. Contact methods require physical contact between the various instruments and the buildings. Any data capture technique and size of the data capture are directly proportional to the time and effort required, with a high dependency on the level of detail (LOD) (Fadli et al., 2016; Pishdad-Bozorgi et al., 2018). BIM modelling is carried out according to the user's requirements and the level of detail captured. The approach used in this study is the capture-to-BIM or scan-to-BIM approach, which generates the BIM systems for existing buildings by first extracting useful information from the data captured using various shape descriptors and then translating that information into a BIM model.

Laser scanning exceeds in capturing the spatial configuration of a space, while photogrammetry is better at collecting visual information, such as texture and colors (Barki et al. 2015). A literature review conducted before this study yielded gaps that motivate us to combine laser scanning and photogrammetry by taking advantage of both methods and overcoming their limitations. Besides, existing as-built CAD drawings were also used in the generation of the BIM model of our case study building.

According to Pishdad-Bozorgi et al. (2018), BIM can be integrated with BMS through a well-defined interoperability plan for exchanging information between BIM tools and a computerized maintenance management system (CMMS). Apart from the difficulties that hinder the accurate generation of BIM models for existing buildings, another challenge to the use of BIM for FM is the lack of interoperability between BIM and multiple computer-aided FM tools (Pärn et al. 2017; Fadli et al., 2016; Yalcinkaya and Singh 2014). It is also complicated, as Oti et al. (2016) noted, to input raw BMS data into BIM models. Further, according to Pishdad-Bozorgi (2017), most facility managers lack insight into how FM activities can be leveraged using BIM. Edirisinghe et al. (2017) noted that, despite its potential, the use of BIM for FM had not been explored extensively in research. Hence, this study examines two significant research areas: the generation of 3D BIM model using different methods and their integration into an existing BMS.

Sacks et al. (2018) stated that BIM is undoubtedly beneficial for FM. El Ammari and Hammad (2019) suggested supporting interactive visual collaboration between the field and the office using BIM-based FM. Patacas et al. (2020) recommended adopting a Common Data Environment (CDE) using open standards to improve facility management. Pishdad-Bozorgi (2018) described the need for IFCs Integrated Project Delivery to enable efficient BIM-enabled handover. However, capturing the existing facility data with no FM requirement at the early stages will result in inadequate FM efficiency (Rodriguez et al., (2017). Fadli et al. (2016) and Fadli and Alsaeed (2019) described BIMbased capture 3D techniques and analyzed benefits and challenges using an extensive SWOT analysis. Al-Qabas et al. (2020) described the accuracy of the information captured that depends on the surrounding factors during the process. Qammaz and Al Maian (2020) stated that competence to deliver is a critical success factor towards the construction industry. The competency to integrate BIM into BMS is lacking, which leads to reliance on 2D as-built for BMS integration.

\section{RESEARCH METHODOLOGY}

A robust literature review was conducted, and three methods of capturing and developing 3D models from existing buildings were identified; these are as-built CAD drawings, 3D laser scanning, and UAV or drones. The 
study explores the time, cost, and accuracy of the three approaches within a defined case study building. The task of the workshop was managed and completed by the project manager with support of the participants in each workshop.

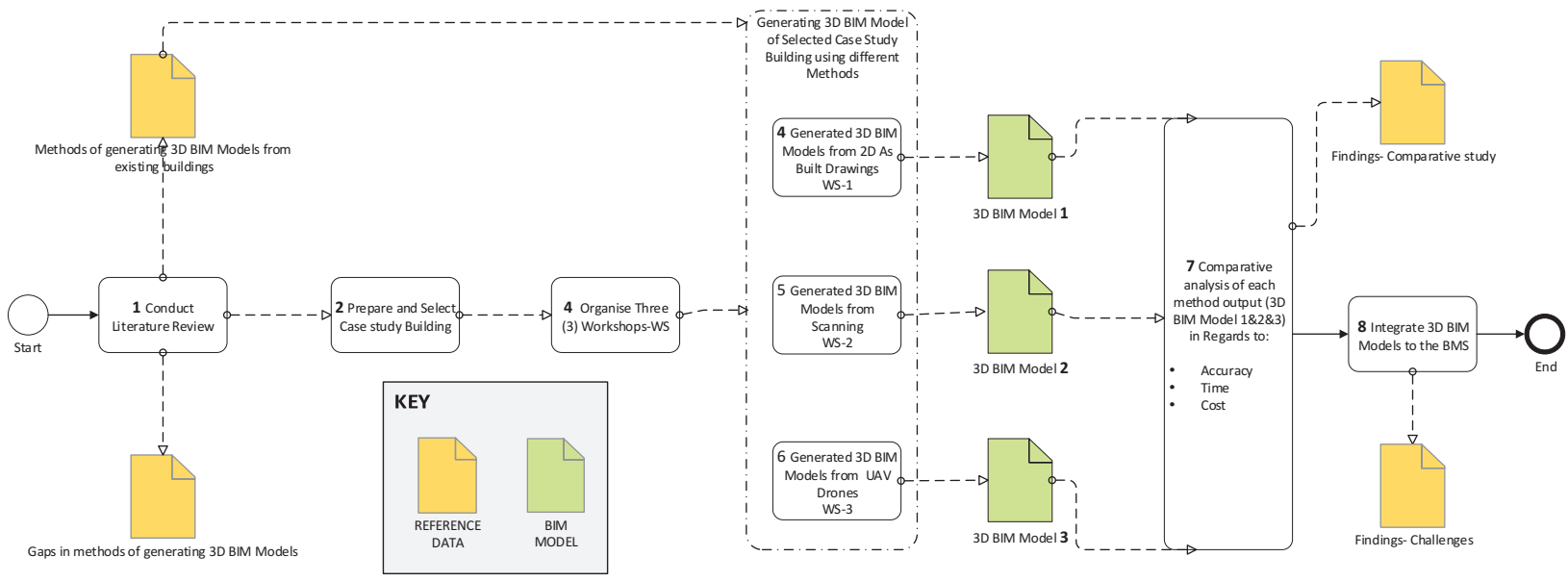

Figure 1. Research study plan.

Table 1. Data capture techniques: An analytical study.

\begin{tabular}{|c|c|c|c|}
\hline $\begin{array}{c}\text { SERIAL } \\
\text { NUMEBR - } \\
\text { PARTICIPANTS }\end{array}$ & $\begin{array}{c}\text { 2D-TO-3D BIM } \\
\text { MODELS (WS-1) } \\
\text { Technology adopted- } \\
\text { Autodesk AutoCAD } \\
\text { and Revit }\end{array}$ & $\begin{array}{l}\text { SCAN-TO-3D BIM } \\
\text { MODELS (WS-2) } \\
\text { Technology adopted- } \\
\text { Autodesk Recap, Revit } \\
\text { and Leica BLK } 360\end{array}$ & $\begin{array}{c}\text { UAV-TO-3D BIM MODELS } \\
\text { (WS-3) } \\
\text { Technology adopted- } \\
\text { Autodesk Recap, DroneDeploy, } \\
\text { DJI Mavic, DJI mission Planner }\end{array}$ \\
\hline 1 & $\begin{array}{l}\text { Facility Management } \\
\text { representative }\end{array}$ & $\begin{array}{l}\text { Facility Management } \\
\text { representative }\end{array}$ & $\begin{array}{l}\text { Facility Management } \\
\text { representative }\end{array}$ \\
\hline 2 & Project Manager & Project Manager & Project Manager \\
\hline 3 & BIM Specialist-Arch & Surveyor & Surveyor \\
\hline 4 & BIM Specialist-Str & Revit Specialist & $\begin{array}{c}\text { Autodesk ReCap Photo } \\
\text { Specialist }\end{array}$ \\
\hline 5 & BIM Specialist-MEP & Leica cyclone Specialist & DroneDeploy Specialist \\
\hline 6 & Draftman- Arch & & \\
\hline 7 & Draftman- Str & & \\
\hline 8 & Draftman- MEP & & \\
\hline NA & Eight participants & Five participants & Five participants \\
\hline
\end{tabular}




\section{CASE STUDY: QU CENTRAL STORES FACILITY-DATA ACQUISITION}

The central stores facility located in Qatar University campus in Doha (capital of Qatar) is used as a case study. The building was selected as it had an exposed ceiling, which is difficult to capture when covered. Our objective aims to generate an integrated, BMS-BIM model of the building. Three methods were used to generate a BIM model of the existing building through three distinct workshops. The generated 3D BIM model was further enhanced with the web-based EcoDomus platform through the integration of BMS. The process followed in this study is shown in Figure 2.

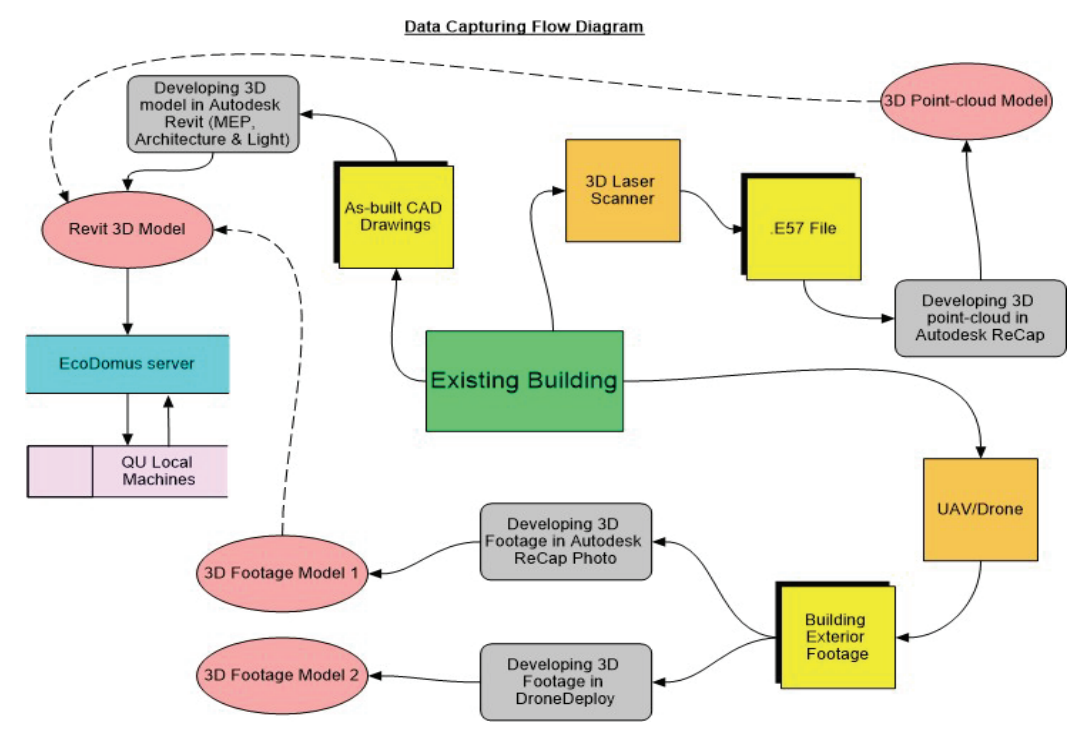

Figure 2. Digital building data capturing the flow.

Figure 3 depicts the integration of BMS to the BIM model using BMS application.

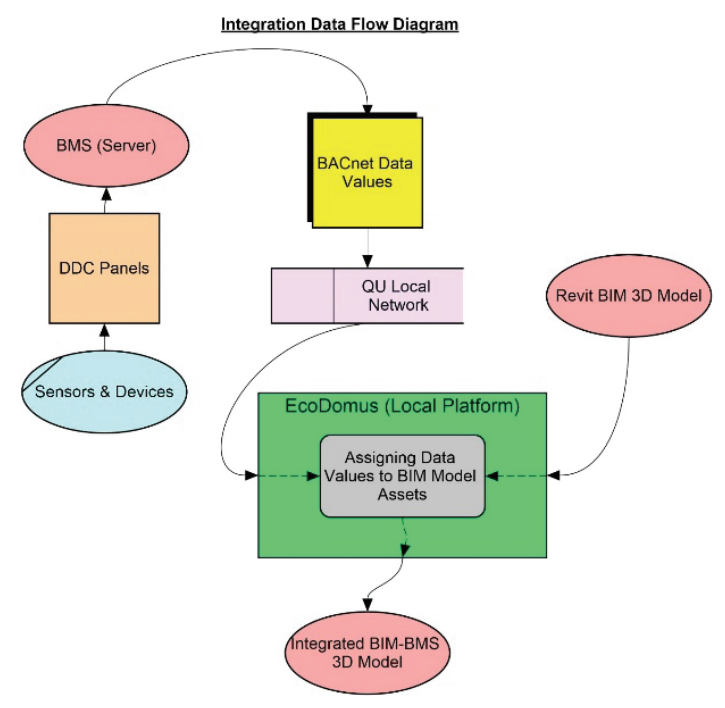

Figure 3. Integration of BIM with BMS. 


\section{QU CENTRAL STORES FACILITY CASE STUDY: GENERATING 3D BIM MODELS THROUGH DIFFERENT METHODS}

QU central stores facility case study comprises three workshops that show the framework used to capture the existing building information to generate 3D BIM models for BMS integration.

\section{Workshop-1: Generating 3D BIM Models from 2D As-Built Drawings}

The first technique required capturing data from 2D as-built drawings. The types of drawings used were architectural, structural, HVAC, and lighting. The data from these drawings covered the areas needed to make a 3D BIM model using Autodesk Revit. This was done in three individual modelling stages (architecture, structure, and MEP) before merging all three outcomes into one coordinated model (final model). Finally, a well-defined BIM 3D model was produced, including building systems such as HVAC and lighting components and architectural and structural objects using the same software (Authoring application). Enhancement and adjustment were conducted to acquire a model of the required quality. Figure 4 illustrates how the capturing process, including all activities and stages, was achieved. The figure demonstrates the applied process, which started with collecting CAD as-built drawings to be used as a reference for the developed BIM model.

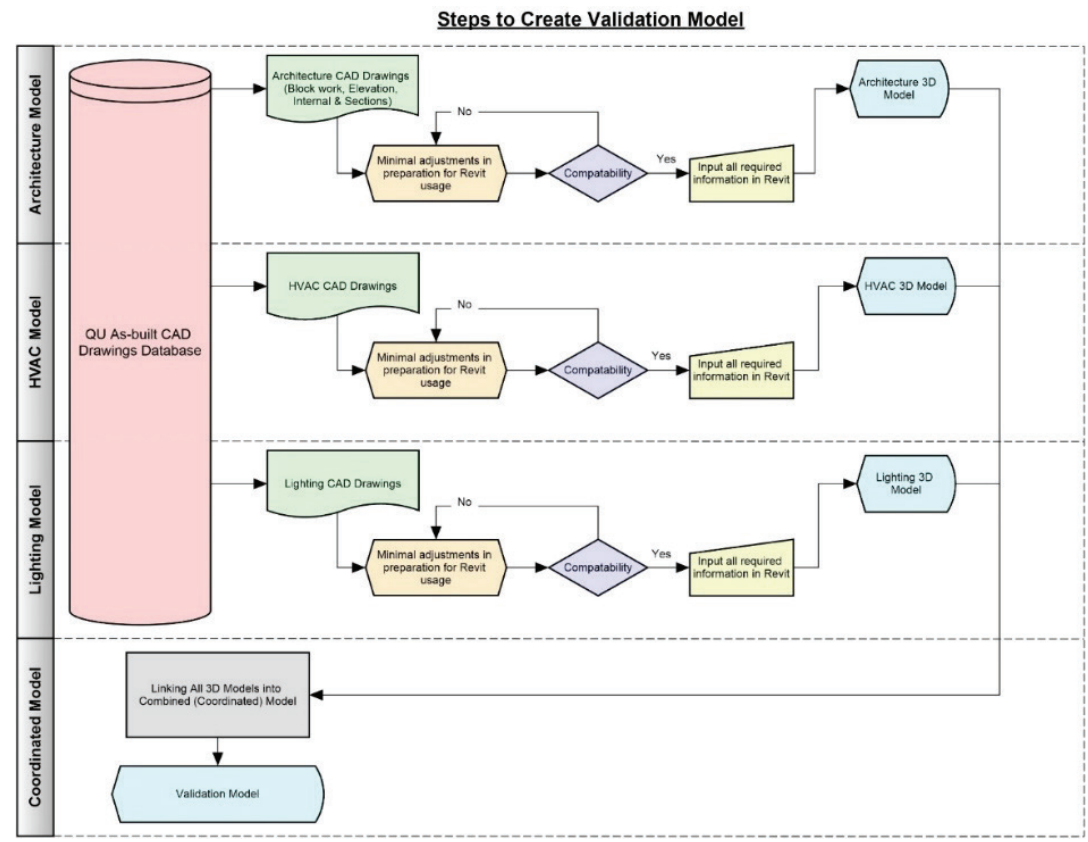

Figure 4. Generating 3D BIM Model from As-Built Drawings flow diagram.

The 2D-to-BIM technique revealed absolute accuracy since it was a CAD conversion process of all architecture, major structural elements, and MEP from the as-built 2D drawings to the integrated 3D model. The time involved for such technique to capture the external façade, building details, and roof details was more 180 man-hours. The cost of the technology (hardware and software-free educational versions) involved was 4000 USD. This method is the most time-consuming among the three capturing techniques. 


\section{Workshop-2: Generating 3D BIM Models from Laser Scanning}

Laser scanning, also referred to as light detection and ranging (LIDAR), is an optical sensor-dependent technique that uses laser scanners to scan the exterior surfaces of objects. The principle of laser scanning lies in converting the spatial data of object surfaces into a 3D point cloud. Laser scanners emit a laser beam that reflects from the surfaces of objects, enabling the distance between the scanner center and the object to be calculated. Thus, it is possible to detect the accurate position (coordinates $\mathrm{X}, \mathrm{Y}$, and $\mathrm{Z}$ ) of objects with respect to the scanner's position.

The 3D laser scanning of the building's interiors was done using a Leica BLK360 scanner. The scanner was configured on-site and operated manually using an iPad. The positioning of the equipment before capturing the various scans is crucial since it affects the final point-cloud model's quality. The scans were imported to fulfil the valid registration to generate a full and final point-cloud model. Total scan positions registration was made for the whole scanning campaign. A complete 3D point-cloud model was generated in both Cyclone and ReCap, although Cyclone is considered an optional step since ReCap is sufficient for exporting the point cloud to Revit. Finally, the model was exported as an RCP file to be imported into Revit for further linking with the coordinated model described above. Figure 5 shows the process of achieving a reality-based point-cloud model.

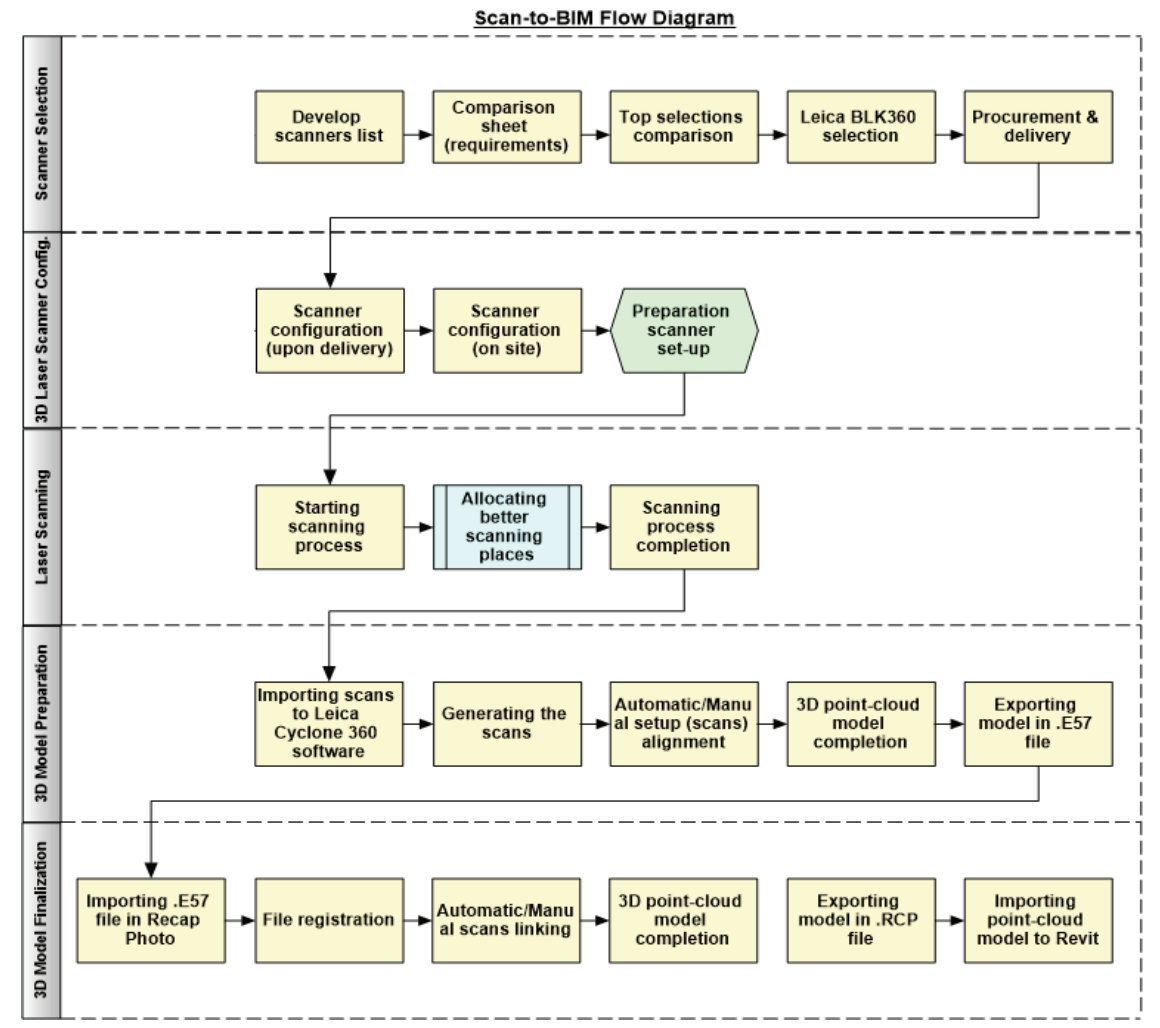

Figure 5. Generating 3D BIM Model from 3D Laser scan flow diagram.

Figure 6 shows alignment of the different models. This method eliminated possible discrepancies, and the outcome was an entirely accurate 3D model. 


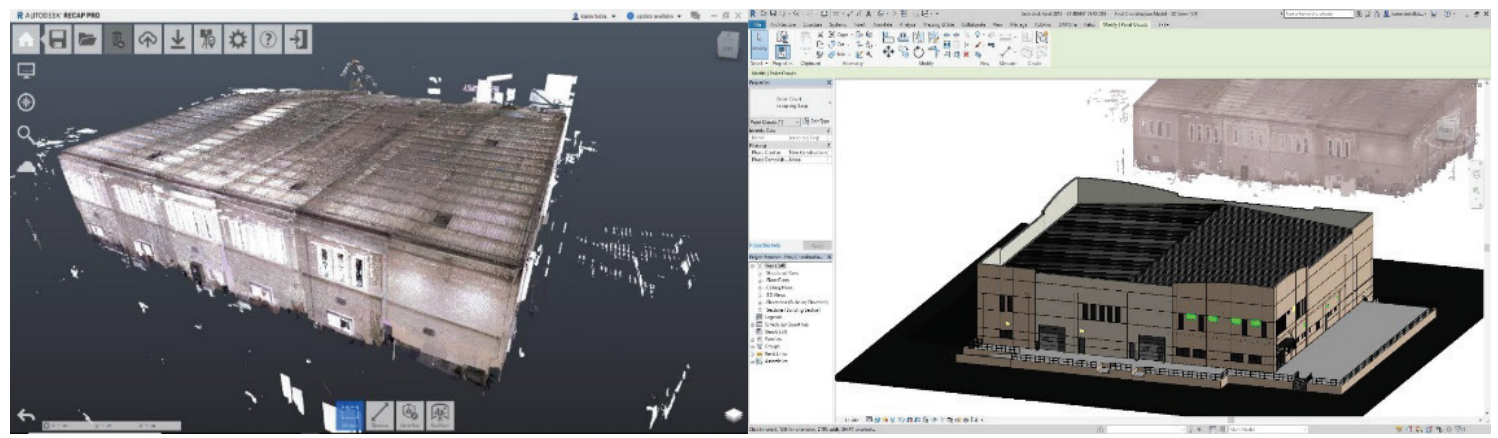

Figure 6. 3D point-cloud model generated from laser scanning and matching origins between as-built and point-cloud models.

The laser scanning process used in this study develops upon existing research. Quintana et al. (2016) presented a 3D semantic data acquisition method that focused on sensing data about indoor structural elements and introduced a data-quality concept that significantly reduced the point cloud to be processed in the scanning process. Xiong et al. (2013) proposed a 6D-based (XYZ+RGB) method that processes dense colored 3D points provided by terrestrial laser scanners and facilitates recognition of smaller components, such as sockets, switches, signs, and extinguishers, commonly situated on walls. This is followed by segmenting the point clouds that match the walls of the building, whereby the color and geometric space of many candidate objects are independently detected, and both of these results are integrated to perform recognition. Lastly, each recognized object is located and inserted into the 3D BIM model.

As previously mentioned, it is necessary to address the NBV problem when performing a laser scan. According to Quintana et al. (2016), to determine the next scanner position in automatic scanning, it is essential to assess the new 3D data obtained from all possible positions of the robot. Since this is not a viable task in a continuous space, the next best scan position is computed in a discretized space. The next step is defining the probabilistic region of interest. The next best position is computed in the voxel space and converted into 3D space.

From each new scanner position, the primary objective is to evaluate the number of occluded structure voxels that would turn into structure voxels. There is some degree of uncertainty of the voxel, which may be located in structural element, as the region of interest is built as a polygonal prism comprising potential structural elements. As the number of occluded voxels in structural element decreases, uncertainty also decreases. The region of interest may change with a new scan.

The accuracy of the scan-to-BIM technique was up to the level of $2 \mathrm{~mm}$. The time involved for such technique to capture the facility is 10 hours (logistics, setup, and cloud processing) with more than 90 scans. The cost of the technology (hardware and software) involved was 20,000 USD.

\section{Workshop-3: Generating 3D BIM Models from UAV}

The UAV method was used to capture the building's exteriors. UAV is a photogrammetric type of data capture, in which a series of overlapped images is processed as one final 3D photogrammetric model. A DJI Inspire 1 was used to implement this technique through the DroneDeploy platform (for mission planning and photo processing). A point cloud application was utilized for the 3D photos that were imported into Revit. Figure 7 shows the UAV capture process. 


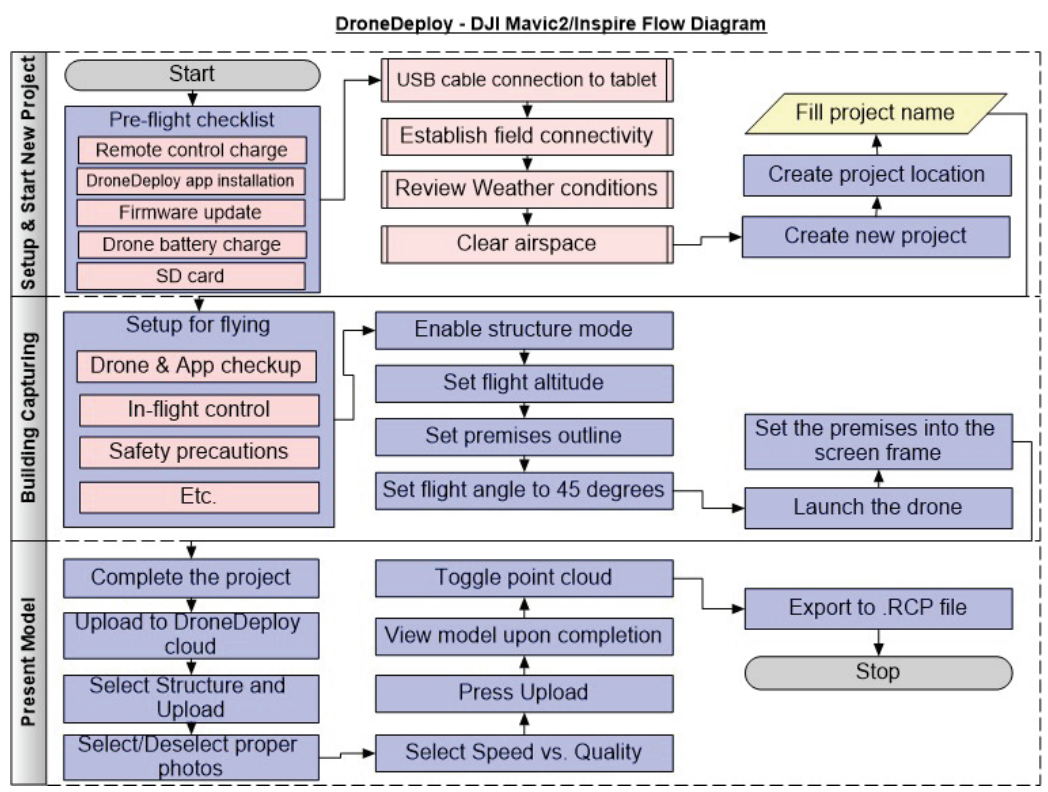

Figure 7. Capturing and processing UAV-to-BIM through the DroneDeploy flow diagram.

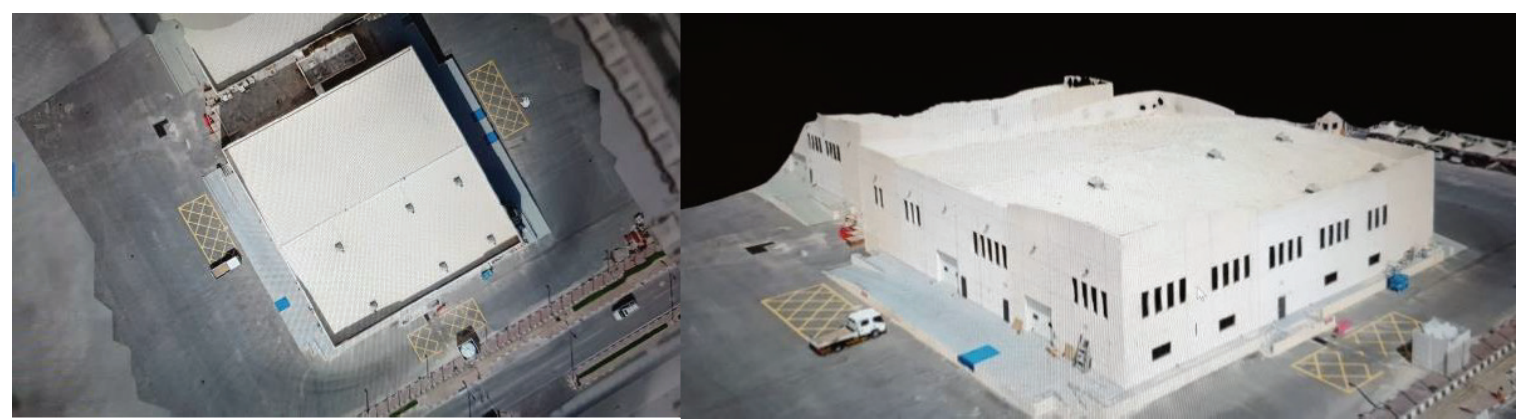

Figure 8. Generating 3D BIM Models from UAV through DroneDeploy.

The process began with the on-site setup of the UAV under consideration of multiple preflight aspects (such as climate and battery charge). The mission plan was set after developing a new project in DroneDeploy. Subsequently, the UAV was launched and completed its mission, and then overlapped photos were generated accordingly. This footage was processed as part of the 3D model development. The file was exported into an RCP extension prior to cleaning the model if required. UAV is the fastest approach to capturing a building's exterior, which is one reason why we chose this technique. UAV-to-BIM was used to complete the reality-based capturing framework. CAD was used to computerize the building skeleton, infrastructure, and foundation (items that cannot be seen). While laser scanning was used for the building interiors, UAV was used for its exteriors.

During this process, it is necessary to ensure the precision of the UAV scan. According to Qu et al. (2014), the precision of laser scanners can be $2-5 \mathrm{~mm}$. Thus, the laser-based point cloud can be used as the ground truth to determine the precision of the UAV-based point cloud (Elhassan 2016). However, the accuracy of the laser-based point cloud must first be verified, for which a laser distance meter can be used. The laser-based point cloud is then 
aligned with a common coordinate system. Before collecting the data, targets can be placed in the scanning location to match the control points that correlate to each point cloud. Deviation analysis is carried out after the cloud points are aligned with the common coordinate system to ascertain the accuracy of the UAV-based point cloud.

The accuracy of the UAV-to-BIM technique was up to the level of $3-5 \mathrm{~cm} / 100 \mathrm{~m}$. The time involved for such technique to capture the external façade, building details, and roof details is two hours for each of the two visits. However, it took 12 hours all together (setup, mission planning, capturing, and postprocessing). The cost of the technology (hardware and software) involved was 1,700 USD.

\section{REVIEW OF METHODS ADOPTED FOR GENERATING 3D BIM MODELS}

In this section, we explain the full process, starting with the CAD-based 3D model and the approach used to capture the drawing's information. Data capture of the building interior and exterior is explained prior to discussing the BIM-BMS integrated model and its implementation, listing all execution steps and outcomes.

As the first step, CAD as-built drawings of the building were collected and processed. These drawings included three main areas: (i) architecture and civil, (ii) HVAC system, and (iii) lighting system. During data capture, each of these systems was considered individually since Autodesk Revit (the BIM software tool) offers a dedicated template for each. Next, as previously described, a coordinated model was developed containing all the necessary infrastructure.

Before laser scanning, a few logistical issues were considered, such as reflective surfaces, black objects, glass parts, and weather conditions. The distance between the Leica scanner and the objects to be scanned should not be less than $0.6 \mathrm{~m}$ or more than $60 \mathrm{~m}$. Importantly, the scanner head should always be mobilized in its dedicated path to prevent any damage. Moreover, the scanning speed and quality are related, as a 40-second scan results in a resolution of $20 \mathrm{~mm}$ at $10 \mathrm{~m}$ distance, while the standard is $10 \mathrm{~mm}$ for 1 minute and 50 seconds, and a high density of $5 \mathrm{~mm}$ is achieved within 3 minutes and 40 seconds.

These actions resulted in a reality-captured point-cloud model. This model was developed to show all facility interior data (dimensions, duct lines, fixture locations, etc.). The point-cloud information was visible, demonstrating the resulting point-cloud model. To validate the BIM model interior (based on as-built drawings), we compared it with the reality-captured laser-scanned model. The verification process began with importing the point-cloud model into Autodesk Revit and assessing the variation between them. Both models were identical to each other without any discrepancies.

The UAV in this study captured the building's exterior as a photogrammetric model. First, the aerial mission parameters needed to be defined prior to receiving flying clearance and after preparing the UAV on site since the selection of the flying mode (automatic/manual), height (distance from ground level), and angle (camera angle for capture) are vital factors in the end model's quality and accuracy. In addition, a physical survey of the building's surroundings (streetlights, construction cranes, etc.) was conducted as a safety precaution. Also, the angle of sunlight is important; therefore, the capture should be performed around noon (between 10 AM and 2 PM), and windy, cloudy, and/or rainy days should be avoided. In the case of manual imaging and 3D mission planning, it is desirable to have $60 \%$ to $70 \%$ of photos overlapping. All the data capturing methods were used to achieve a complete and precise 3D BIM Model to integrated into the BMS. 


\section{INTEGRATION OF 3D BIM MODELS INTO THE BMS}

This study aimed to digitalize facilities using BIM principles for FM. Therefore, integrating the captured BIM model with existing BMS was a critical part of the process. BMS is a vital tool that manages all building utilities and infrastructure through real-time sensing. Integrating BIM with BMS allows users to fully leverage the informational benefits of BIM, thus yielding optimal value for FM. In order to achieve full integration in this study, we configured and used a platform known as EcoDomus. This platform is integrative not only with BMS, but also with space management, maintenance systems, geographical information systems, and project management. The BMS application operation does not rely on coding or programming protocols; instead, it is a global server-based information exchange platform (EcoDomus, 2019). To synchronize BIM elements with BMS values (BACnet), we conducted a preintegration process before full integration. Due to some communication constraints between the university and the global BMS application server, a local machine (PC) was configured to act as a local server-based platform for data exchange. Figure 11 shows the process flow implemented to complete the integration.

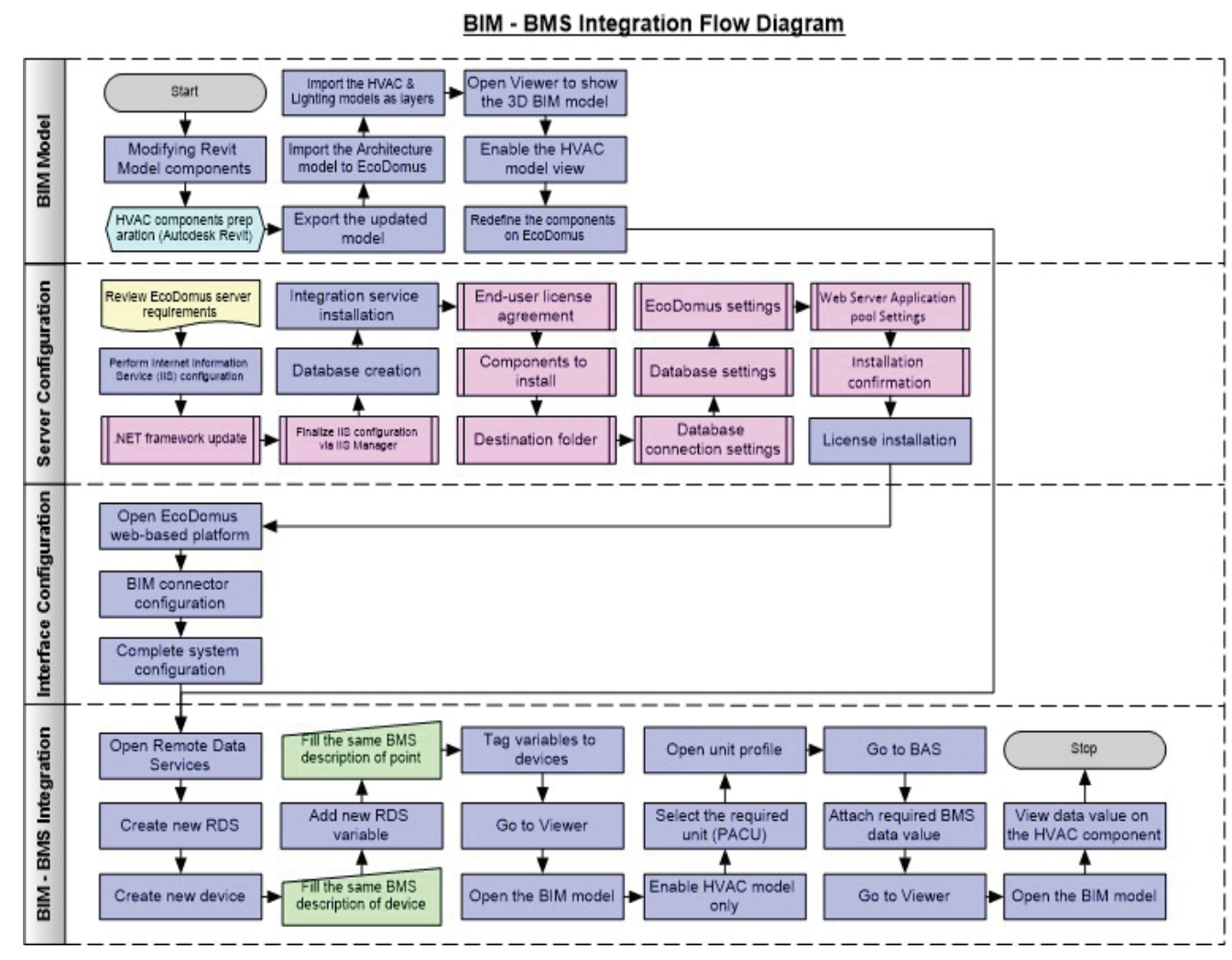

Figure 11. Integration of BIM to BMS flow diagram.

The BIM-BMS integration was accomplished after the completion of a reality-based coordinated BIM model linked to the point cloud (interior) and photogrammetry (exterior). The interface between the final BIM and live BMS was performed using the integration platform of the BMS application to exchange data between both parties. Preintegration was a critical step for achieving a fully integrative platform since ensuring communication among all elements was challenging. Another crucial process was the local server configuration. The BMS application configuration was finalized in three main stages, which are as follows: 
- $\quad$ The first was running the web browser using the project URL.

- The second was testing the URL in the BIM Connector plugin before importing the model.

- The last was the authentication of the platform in terms of permitting BMS application activity within Microsoft Windows.

Integration was initiated by scanning the BACnet values available as a verification of the communication with BMS. After ensuring a proper connection, the attachment of the BMS real-time values with Remote Data Services (RDS) devices was required; the development of the RDS devices with a similar BMS readings description had already been completed. The 3D viewer was accessed to review the synchronization of the BMS real-time values to finish the process. Figure 12 shows the adopted BMS application iOS app user interface.

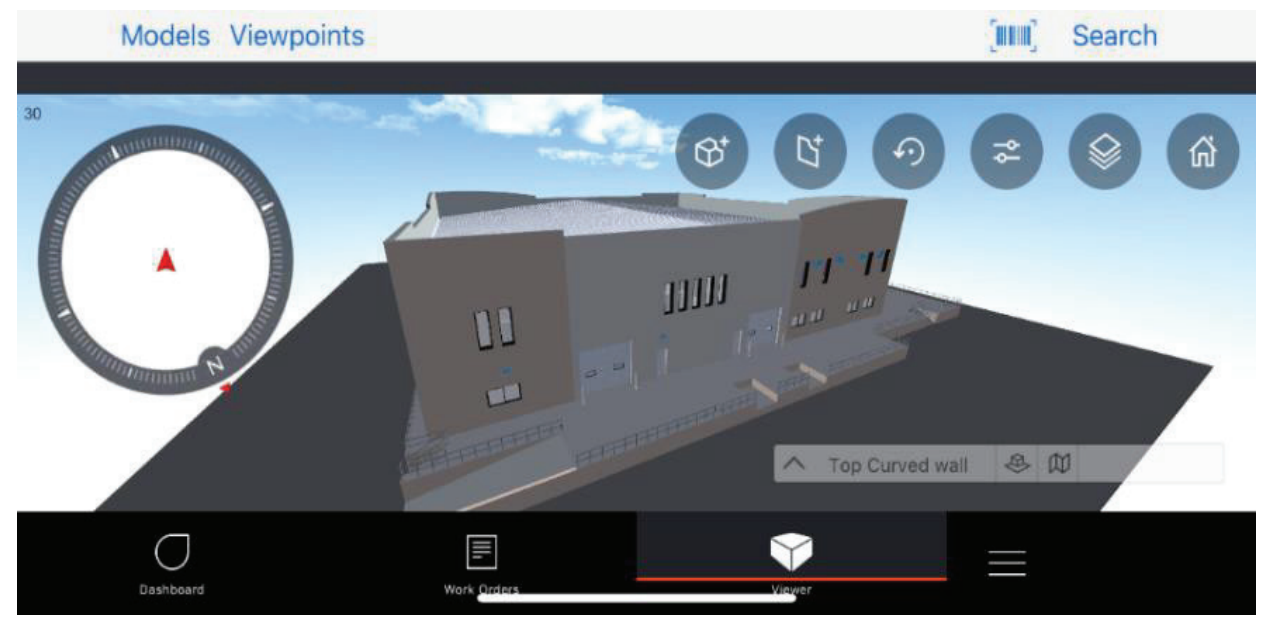

Figure 12. Adopted BMS application iOS app user interface: integration of BIM to BMS.

\section{RESULTS AND DISCUSSION}

The case study outcomes show that CAD-to-BIM was the most time consuming while using minimum resources. In contrast, BMS integration consumed the least time and had the lowest cost but required substantial resources. However, scan-to-BIM and UAV-to-BIM showed a logical relationship between cost and time, requiring approximately the same resource allocation. This research adds value in relation to scan-to-BIM and BIM-BMS integration by detailing the methodology for a nonprogramming protocol integration of BMS with BIM, while providing information about scanning techniques that contribute to the generation of integrated BIM-BMS platform. The latter did not require any additional hardware (e.g., gateways) to be accomplished.

A summary review table depicts the accuracy of the three capturing methods (Table 2). This study involved multiple types of resources, although costs are considered only in terms of the tools and assets required (Leica BLK360 scanner, DJI Inspire 1, MSI laptop, and the accompanying software licenses). Timewise, the CAD-to-BIM required 160.25 hours for the manual conversion of the as-built drawings to the BIM model. The scanning, UAV, and integration needed a few permissions to be obtained such as facility access and aviation clearance. The on-site data capture mostly consisted of laser scanning, with 7 hours to scan the building's interior and 1 hour each for UAV (mission planning and photo processing) and integration (configuring BMS server communication). 
Table 2. Comparative analysis (accuracy) of the different method of generating 3D BIM Models.

\begin{tabular}{|c|c|c|}
\hline $\begin{array}{c}\text { Methods of 3D BIM } \\
\text { Model generation }\end{array}$ & DESCRIPTION WITH DIMENSIONS IN DIFFERENT \\
APPLICATIONS \\
$\begin{array}{c}\text { BIM 3D Model-1 Generated } \\
\text { from (2D As-Built) } \\
\text { External Dimension- } \\
\text { 45.330m } \\
\text { AutoCAD }\end{array}$ \\
$\begin{array}{c}\text { BIM 3D Model -2 Generated } \\
\text { from (Scanning) } \\
\text { External Dimension- } \\
\text { 45.330m } \\
\text { Revit }\end{array}$
\end{tabular}

Data processing took 4 hours (1 hour each for scanning and UAV to process the captured data), with 2 hours allocated for configuring the BMS application parameters before the data points assignment. The point-cloud model development took 15.5 hours to manually register the scans and develop the model, 4 hours in the point cloud application Photo to develop a photogrammetric model in the Autodesk cloud automatically, and another 4 hours to assign the BMS values in BMS application to the proper BIM equipment/item. Table 3 shows the approximate cost and time spent in this study.

Individuals with diverse knowledge backgrounds and experiences are essential for the capture and integration processes. Surveyors were required on-site for laser scanning and UAV capture, along with an IT specialist for the BMS server communication. The data processing required only a BMS application specialist to manually process the BMS data points, as other processes were performed automatically through software or online cloud computing. The majority of human resources involved in this study were needed in 3D model development. Four people with different knowledge backgrounds were assigned to the BIM-BMS model, three to the point-cloud representation, two to photogrammetry, and one to the Revit drafting. 
Table 3. Accuracy, cost, time, and integration to the BMS by data capture techniques.

\begin{tabular}{|c|c|c|c|c|}
\hline & $\begin{array}{c}\text { CAD-to-3D } \\
\text { BIM Models- } \\
1\end{array}$ & $\begin{array}{c}\text { Scan-to-3D } \\
\text { BIM Models- } \\
2\end{array}$ & $\begin{array}{c}\text { UAV-to-3D } \\
\text { BIM Models- } \\
\mathbf{3}\end{array}$ & $\begin{array}{l}\text { 3D BIM } \\
\text { Models to } \\
\text { BMS }\end{array}$ \\
\hline $\begin{array}{c}\text { MODEL } \\
\text { DESCRIPTION }\end{array}$ & $\begin{array}{l}\text { Architecture } \\
\text { Structural } \\
\text { MEP; Fittings, } \\
\text { fixtures, } \\
\text { non- textured } \\
\text { model } \\
\text { (Interior and } \\
\text { Exterior) }\end{array}$ & $\begin{array}{c}\text { Architecture } \\
\text { Structural } \\
\text { MEP } \\
\text { Full 3D textured } \\
\text { model } \\
\text { (Interior and } \\
\text { Exterior) } \\
\text { Point cloud } \\
\text { based on laser } \\
\text { beams }\end{array}$ & $\begin{array}{l}\text { Full 3D textured } \\
\text { model } \\
\text { (Exterior only) } \\
\text { Point cloud } \\
\text { based on } \\
\text { photogrammetry }\end{array}$ & NA \\
\hline DATA SOURCE & $\begin{array}{c}\text { As-Built } \\
\text { drawings and } \\
\text { specifications }\end{array}$ & $\begin{array}{c}\text { Access to } \\
\text { building only }\end{array}$ & $\begin{array}{c}\text { Access to } \\
\text { building only }\end{array}$ & NA \\
\hline $\operatorname{CosT}(\$)$ & $(\sim \mathrm{US} 4000)$ & $(\sim \mathrm{US} \$ 20,000)$ & $(\sim \mathrm{US} \$ 1,700)$ & ( US $\$ 5,040)$ \\
\hline TIME (HOURS) & 160.25 & 23.5 & 6 & 4 \\
\hline $\begin{array}{c}\text { MINIMUM } \\
\text { DATA } \\
\text { ACCURACY (\%) }\end{array}$ & 100 & 99.4 & 98.9 & 100 \\
\hline $\begin{array}{c}\text { Accuracy } \\
\text { consideration }\end{array}$ & Fully accurate & $\begin{array}{l}\text { Max error } 2 \mathrm{~cm} / \\
\text { any dimension }\end{array}$ & $\begin{array}{c}\text { Max } 4 \text { to } 5 \mathrm{~cm} / \\
100 \mathrm{~m}\end{array}$ & NA \\
\hline
\end{tabular}

For BIM model analysis, we used multiple approaches based on capture technique, with CAD, scanning, and UAV-to-BIM data assessed according to their dimensional variation and integration analyzed from the perspective of a real-time synchronization response. We, therefore, divide quality evaluation into three main sections: exterior evaluation (as-built drawings, Revit model, and UAV capture), interior evaluation (as-built drawings and point-cloud model), and integration (value readings in BMS application). The results showed an excellent level of quality as the three measurements were the same, with a negligible variance of $+1 \mathrm{~mm}$ in the UAV capture. For the interior, comparison of the as-built drawings and the BIM model comparison showed a $0 \%$ variance, achieving a $100 \%$ correspondence among the three capture techniques.

\section{BRIDGING THE GAP AND CONTRIBUTION TO KNOWLEDGE}

There are more existing buildings with no BIM models than new builds with fully BIM models. This indicates a need for capturing the existing buildings for digital monitoring and operation towards reduced cost and emissions. This paper presents a detailed comparison of the three different data capturing techniques to transform existing 
facilities digitally. Additionally, it presents how such captured data could be integrated into existing BMS systems to enhance FM operations and maintenance. The study shows each technique's technology-based platforms, cost, associated time to implement, advantages, and disadvantages, and also when and where to use each capturing technique.

If CAD drawings are unavailable, the point-cloud laser-scanned model can be used as the data source for the building's BIM model interior in a similar manner. A UAV photogrammetric model can then be used (instead of asbuilt drawings) for the exterior by exporting this model to 2D drawings. Another way this framework is versatile is that any BMS with BACnet protocol can be integrated with the Autodesk Revit BIM model. The result is a single platform that uses BIM to centralize all building data and that can help FM teams access and retrieve data quickly.

The study also contributes to the existing literature. It presents three different conversion frameworks to accurately capture existing building information: CAD-to-BIM, laser scanner-to-BIM, and UAV-to-BIM. However, each approach has its advantages and disadvantages. The choice of technology depends on many parameters, like the level of detail required for the BIM model and time and cost considerations. As technology evolves, the study recommends combining different scanning techniques to overcome the limitations of different technologies and verify the result.

\section{CONCLUSION}

This study presents an approach to combining different scanning technologies for accurate BIM model generation of existing buildings to integrate BIM with BMS. It uses a fusion of 3D laser scanning and 3D photogrammetry for automatic and precise BIM models, thus overcoming one of the technical barriers to adopting BIM for existing buildings. Our combination of two scanning technologies resulted in a highly accurate BIM model, as evaluated compared to the as-built data. Even if there are as-built drawings available, BIM conversion is a cumbersome process and takes a lot of time and resources compared to the framework explained in this paper.

Our work contributes to a greater understanding of the development of BIM models for existing buildings. In other contexts, different scanning technologies may be used depending on the level of detail required for the BIM model. We also note that additional research and development is needed to overcome some remaining challenges. For one, different types of BMS may or may not be able to be integrated with BIM; hence, there is a need for more research efforts that address the integration of BIM models with existing BMS. Although advanced scanning technologies offer a significant advantage over traditional CAD to BIM modelling, cost remains a significant obstacle.

Furthermore, while 3D laser scanning and photogrammetry using drones can go a long way towards generating an initially accurate generation of a BIM model, they still face challenges in capturing the building information concealed inside structural elements. Based on this research, the best strategy currently available is to use a combination of different scanning technologies wherever possible to capture building data for conversion into BIM models. This strategy enables users to take advantage of the benefits of varying scanning techniques while, at the same time, overcoming their limitations. Future research could aim to further identify the gaps in BIM adoptions for the operational and maintenance of facilities. BIM-FM integration can reduce maintenance costs and time compared to traditional-based techniques. 


\section{ACKNOWLEDGMENT}

The authors would like to thank the College of Engineering, Departments of Architecture and Civil/Architectural Engineering at Qatar University, for their support and facilities provided for this research study. The authors would also like to thank Mr. Ramzi Qamar (BIMTEC), Mr. Ricardo Camarinha (BIMTEC), Mr. Manuel Luis (BIMTEC), Mr. Hossam Khaled (SHIFTO), Mr. Igor Starkov (EcoDomus), and Mr. Victor Chekalin (EcoDomus) for their support and help in this research.

\section{LIMITATIONS}

Specific applications were used for the case study. The accuracy can vary depending on the accuracy of the technology applied for existing building capture (scanning and UAV). The cost of each capture technique would also vary depending on the choice of technology and license fees. The cost was focused on hardware and software only with exception of man-hours for each capture technique.

\section{REFERENCES}

Al-Qabas, I.A. Farahan, MH \& Fawzy, HE. 2020. Surrounding factors' influence on the accuracy of the Digital level and Total station in Journal of Engineering Research 8(4): 45-62.

Barki, H., Fadli, F., Shaat, A., Boguslawski, P., \& Mahdjoubi, L. 2015. BIM models generation from 2D CAD drawings and 3D scans: an analysis of challenges and opportunities for AEC practitioners. WIT Transactions on the Built Environment, 1: 369-380.

Carbonari, G., Stravoravdis, S., \& Gausden, C. 2018. "Improving FM task efficiency through BIM: a proposal for BIM implementation.” Journal of Corporate Real Estate, Univ Greenwich, Dept Built Environm, London, England 20(1): 4-15.

EcoDomus. (2019). EcoDomus - Lifecycle BIM Company. <https://ecodomus.com/> (Apr. 18, 2019).

Edirisinghe, R., London, K. A., Kalutara, P., \& Aranda-Mena, G. (2017). Building information modelling for facility management: are we there yet?. Engineering, Construction, and Architectural Management, 24(6): 1119-1154.

El Ammari, K. \& Hammad, A. 2019. Remote interactive collaboration in facilities management using BIMbased mixed reality. Automation in Construction, 107, art. no. 102940

Elhassan, W. (2016). 3D Modeling of Indoor Building Geometry Using Unmanned Aerial Systems. Concordia University, Montreal, Quebec, Canada.

Fadli, F., \& Alsaeed, M. 2019. Digitizing Vanishing Architectural Heritage; The Design and Development of Qatar Historic Buildings Information Modeling [Q-HBIM] Platform. Sustainability 2019, 11(9): 2501; https://doi.org/10.3390/su11092501

Fadli, F., Barki, H., Shaat, A., Mahdjoubi, L., Boguslawski, P. \& Zverovich, V. 2016. 3D capture techniques for BIM enabled LCM. IFIP Advances in Information and Communication Technology, 2016, 467: 183-192

Leica. (2019). Leica BLK360 Imaging Laser Scanner | Leica Geosystems." <https://leicageosystems.com/products/laser-scanners/scanners/blk360> (Apr. 18, 2019).

Oti, A. H., Kurul, E., Cheung, F., \& Tah, J. 2016. The Utilization of BMS in BIM for Facility Management. CIB World Building Congress, Tampere, Finland, 224-235.

Pärn, E. A., Edwards, D. J., \& Sing, M. C. P. 2017. The building information modelling trajectory in facilities management: A review. Automation in Construction, 75: 45-55. 
Patacas, J., Dawood, N. \& Kassem, M. 2020. BIM for facilities management: BIM for facilities management: A framework and a common data environment using open standards

Automation in Construction, 120, art. no. 103366

Pishdad-Bozorgi, P. 2017. Future Smart Facilities: State-of-the-Art BIM-Enabled Facility Management. Journal of Construction Engineering and Management, 143(9), 02517006.

Pishdad-Bozorgi, P., Gao, X., Eastman, C., \& Self, A. P. 2018. Planning and developing facility managementenabled building information model (FM-enabled BIM). Automation in Construction, 87: 22-38.

Qammaz, ASBU \& AIMaian, RY. 2020. A critical success factors model for effective implementation of risk management process in the construction projects in Journal of Engineering Research 8(3): 51-70

Qu, T., Coco, J., Rönnäng, M., \& Sun, W. 2014. Challenges and Trends of Implementation of 3D Point Cloud Technologies in Building Information Modeling (BIM): Case Studies. International Conference on Computing in Civil and Building Engineering, Orlando, Florida, United States, 809-816.

Quintana, B., Prieto, S. A., Adán, A., \& Vázquez, A. S. 2016. Semantic scan planning for indoor structural elements of buildings. Advanced Engineering Informatics, Elsevier Ltd, 30(4): 643-659.

Rodriguez-Trejoa S., Ahmad AM, Mian-Atif H., Dawooda, H., Vukovica, V., Kassem, M., Naji, KK. \& Dawood, N. 2017. Hierarchy Based Information Requirements for Sustainable Operations of Buildings in Qatar. Sustainable Cities and Society. 32:435 - 448

Sacks, R. Eastman, C., Lee, G., \& Teicholz, P. 2018. BIM Handbook: A Guide to Building Information Modeling for Owners, Designers, Engineers, Contractors, and Facility Managers, 3rd Edition, 688 pages. Wiley. ISBN: 978-1-119-28753-7

Volk, R., Stengel, J., \& Schultmann, F. 2014. Building Information Modeling (BIM) for existing buildings Literature review and future needs. Automation in Construction, 38: 109-127.

Wong, J. K. W., Ge, J. \& He, S. X. 2018. Digitisation in facilities management: A literature review and future research directions. Automation in Construction, 92: 312-326.

Xiong, X., Adan, A., Akinci, B., \& Huber, D. 2013. Automatic creation of semantically rich 3D building models from laser scanner data. Automation in Construction, 31: 325-337.

Yalcinkaya, M., \& Singh, V. 2014. Building Information Modeling (BIM) for Facilities Management - Literature Review and Future Needs. Product Lifecycle Management for a Global Market, IFIP International Conference on Product Lifecycle Management, Springer, Berlin, Heidelberg, 1-10.

Yin, M., Ye, Z., Tang, L., \& Li, S. (2018). An Automated Layer Classification Method for Converting CAD Drawings to 3D BIM Models. Proceedings of the 35th CIB W78 2018 Conference: IT in Design, construction, and Management, Springer, Chicago, United States, 67-76. 